\title{
ОСОБЕННОСТИ ФОРМИРОВАНИЯ КОНСОЛИДИРОВАННЫЙ ФИНАНСОВОЙ ОТЧЕТНОСТИ ДЛЯ ОРГАНИЗАЦИЙ БАНКОВСКОЙ СФЕРЫ
}

\author{
(c) 2021 Демина Ирина Дмитриевна \\ доктор экономический наук, профессор \\ профессор Департамента аудита и корпоративной отчетности \\ Факультета налогов, аудита и бизнес-анализа \\ Финансовый университет при Правительстве Российской Федерации, Россия, Москва \\ E-mail: IDDemina@fa.ru
}

\section{(c) 2021 Просвирнин Павел Михайлович \\ Специалист по аудиту КПМГ \\ E-mail: pprosvirnin@kpmg.ru}

В статье рассмотрены особенности составления консолидированной отчетности организаций банковской сферы с учетом применения автоматизированных информационных систем, обобщены некоторые методические положения и практические вопросы формирования консолидированной финансовой отчетности, а также даны предложения по их развитию.

Ключевые слова: консолидированная отчетность, организации банковской сферы, МСФО, РСБУ, ФСБУ, автоматизация, консолидационные процедуры. Методика консолидации, статья расходов, ключевые индикаторы, заинтересованные лица, инвесторы, заинтересованные пользователи, элиминирование внутригрупповых остатков

На современном этапе формирования экономики и рыночных отношений в любой организации особое значение занимает финансовая отчетность. Существенная часть отечественных предприятий подчеркивают необходимость объединения капитальных ресурсов для последующей эффективной работы хозяйственной деятельности. Для продуктивной деятельности, направленной на выполнение четких производственных задач, большинство предприятий нацелены на процесс укрупнения капитала и наращивание производственных мощностей, что помогает получить больше возможностей для реализации стратегических задач, повышения финансового и устойчивого состояния предприятия.

В последнее время большинство отечественных предприятий объединяются путем слияний материнской с дочерней компанией. Путем сложного объединения компании образуют экономические и правовые отношения, в связи с чем повышается их значение в формировании государства и экономики страны в целом. Тем самым у государства тоже повышается интерес к таким компаниям. Государственные структуры контролируют их хозяйственную деятельность, а также экономическое состояние соединенных предприятий посредством проведения анализа

консолидации финансовой отчетности, так как не всегда можно дать полную оценку общего финансового-экономического состояния предприятий.

Особое значение на таких предприятиях занимает консолидированная финансовая отчетность. Данное обстоятельство заключается в том, что большинство отечественных предприятий стремятся выйти на международную арену, поэтому роль консолидированной отчетности с каждым годом только растет.

В современных условиях интенсивное развитие предпринимательской деятельности обусловлено большим числом конкурентных предприятий и компаний, поэтому большая часть отечественных компаний нацелена на грамотное управление и учет финансовой отчетности, чтобы повысить значение консолидированной финансовой отчетности.

Важное значение в организациях занимает сама подготовка к формированию отчетности, так как объективная консолидированная финансовая отчетность должна быть прозрачной для всех заинтересованных лиц в получении актуальной информации финансового состояния предприятия. K таким лицам относятся: инвесторы, кредиторы, партнеры и другие лица, которые стремятся получить полноценную ин- 
формацию о консолидированном финансовом состоянии предприятии.

Консолидированная отчетность помогает получить актуальную информацию о любом предприятии, о его ключевых индикаторах, с помощью которых заинтересованные лица могут увидеть полную картину экономического состояния предприятия, его предприимчивость, жизненную стадию роста или, напротив, его затухание, а также его слабые и сильные стороны.

Все эти вопросы остаются актуальными для банковской сферы.

В настоящее время консолидация в основном происходит с компаниями, которые напрямую не относятся к банковскому сектору. Компании могут быть разноплановые, например, в структуре дочерних организаций банков есть компании занимающиеся лизингом. Также могут быть компании, занимающиеся сельскохозяйственными работами. Тем самым финансовая отчетность банковской группы начинает состоять не только из банка, но и организаций, которые никак не относятся к кредитному рынку. Данный факт влияет на процесс формирования консолидированной финансовой отчетности.

Это влияет на процесс трансформации и консолидации отчетности. Главное отличие банка и коммерческих организаций, это разные планы счетов, которые изначально применяются в РСБУ отчетности. Сложность заключается в том, что невозможно применение кодов трансформации для подготовки трансформации сумм от РСБУ к МСФО [6]. Таким образом, получается, что изначально процесс трансформации по каждой компании собирается по-своему в связи с особенностями сферы, в которой представлена организация.

Также особенностью формирования консолидированной финансовой отчетности является правильное соотнесения тех или иных статей отчета о финансовом положение и отчета о прибыли или убытке между материнской компанией, то есть банком, и дочерней организацией [5]. Исходя из форм отчетности, что по РСБУ, что по МСФО, разница больше всего будет прослеживаться в отчете о прибыли или убытке. В отчете о финансовом положении разница между банком и коммерческой организаций может быть в статье «кредиты выданные клиентам», так как это основная статья для многих банков. Также, разницы в соответствии форм могут наблюдаться в обязательствах банка и организации. В банке в обязательствах больше всего представлены статьи «Средства клиентов», «Средства других банков», которые не свойственны другим организациям. Тем самым в большинстве своем, при консолидации форм отчетности банка и коммерческой организации, более вероятно, что суммы по дочерней компании будут находится в «Прочих активах» или «Прочих обязательствах». Только если сумма, которая консолидируется с материнской компанией не является существенной и ее решают выделить в отдельную строку в отчетности. Рассматривая отчет о прибыли или убытке, тоже можно заметить, что есть различия по статьям, представленным в финансовой отчетности. У банка в большинстве своем статьи состоят из «Процентных доходов по кредитам» и «Процентных расходов по кредитам и депозитам». В данном случае при консолидации, практически маловероятно, что у дочерних организаций также есть расходы или доходы по представленным кредитам или депозитам. Статьями, которые более вероятно будут консолидироваться в банках с другими коммерческими организациями, являются операционные доходы и расходы. Самая простая консолидация будет по таким расходам как: зарплата, амортизация основных средств, аренда, административные расходы и прочие расходы.

Еще одной из отличительных особенностей и, возможно главных, при консолидации финансовой отчетности в банковских группах, является элиминирование внутригрупповых остатков. Если у банка есть дочерние компании, то логично, что они в свою очередь могут брать у него кредит, так как это экономически выгоднее. Так дочерняя организация ООО «Тойота банк» может и не имела кредит на конец отчетного периода, но нельзя отрицать, что она погасила его до конца года. А вот дочерние компании ПАО КБ «Центр-инвест», каждая из них имеет кредит в своем банке. Тем самым данные кредиты и доходы по ним элиминируются при составлении конечной консолидированной финансовой отчетности. Также многие дочерние компании держат свои деньги на расчетных счетах в банках или на депозитах. Тем самым можно заключить, что больше всего элиминации происходит по двум статьям, это по кредитам выданным клиентам и причитающийся доход по ним, и средства клиентов и расход по ним. Другие статьи в основном консолидируются, так как они в основном не взаимосвязаны. 
Следующей особенностью при консолидации финансовой отчетности, является уменьшение валюты баланса после осуществления всех консолидационных проводок. Материнские компании предоставляют крупные кредиты своим дочерним компаниям, тем самым в РСБУ валюта баланса выше, чем конечная сумма в консолидированной финансовой отчетности.

Решение задач, которое ставится при консолидации финансовой отчетности невозможно без применения различных вариантов систематизирования информации [4]. Таким образом, отдельного внимания заслуживают вопросы, непосредственно связанные с автоматизацией бухгалтерского учета, так как автоматизирован- ные системы учеты призваны ускорить формирование консолидированной финансовой отчетности. Такой подход, может позволить избежать ошибок, которые происходят при работе с большими объемами информации, которые в последующим имеют непосредственное значение на финансовые показатели Группы [2]. При автоматизации формирования консолидированной финансовой отчетности группы используются следующие подходы, которые будут представлены ниже на рисунке 1. Данные подходы являются неотъемлемой частью формирования финансовой отчетности, а также могут обеспечить качество информации и в перспективе снизить затраты на сборку и группировку отчетности.

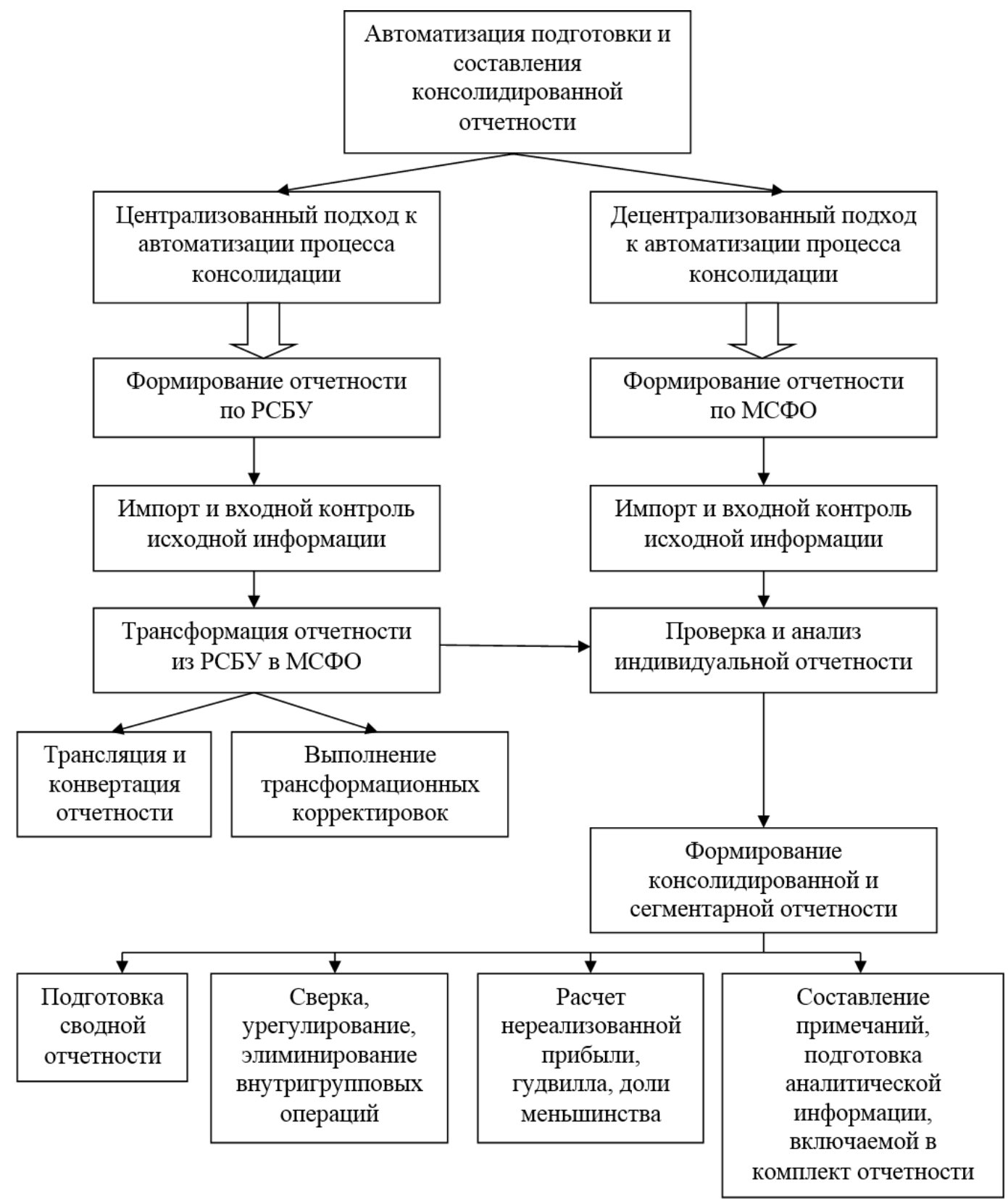

Рисунок 1. Последовательность консолидационных процедур при составлении отчетности 
Как видно из рисунка 1, выделено и будет рассмотрено две системы автоматизации и подготовки финансовой отчётности. Первая система, которая будет проанализирована - централизированная. Принцип работы централизированной системы заключается в том, что материнская компания запрашивает отчетность дочерних компаний, составленную по РСБУ. В дальнейшим при получении от всех дочерних компаний отчетностей составленных по РСБУ, материнская компания осуществляет трансформационные проводки для формирования отчетности по МСФО. Централизированная система очень полезна, так как может решить ряд проблем. Данные проблемы прежде всего связаны с комплексностью трансформационных проводок и сложностью перехода между разными учетными регистрами. Необходимо заметить, что в автоматизации процесса трансформации и последующего формирования консолидированной финансовой отчетности, задействована только материнская организация.

Если рассматривать децентрализованную автоматизированную систему, то в данном случае и материнская и дочерние компании должны участвовать в трансформации и консолидации финансовой отчетности. Таким образом, дочерние компании обязаны вести параллельный учет. Бухгалтерский учет должен вестись как по российским стандартам бухгалтерского учета (РСБУ), так и по международным стандартам финансовой отчетности (МСФО). Консолидация финансовой отчетности при такой системе, будет формироваться на основе учетных данных, которые сформированы по правилам МСФО. Ре- шение о применение децентрализованной автоматизированной системы требует взвешенного решения, так как при автоматизации процесса, потребуются более комплексные IT-решения, для возможности учета по МСФО как для материнской так и для дочерней компании. Для того, чтобы облегчить выбор для организации какую систему ей лучше использовать, в таблице 1 будет представлен ряд характеристик, при которых организации будет легче выбрать систему автоматизированной подготовки финансовой отчетности.

Централизированный подход подойдет компаниям более мелким где процесс консолидации носит простой характер и не включает большое количество трансформационных и консолидационных проводок. Также этот подход более экономичный и к нему не требуется закупка программного обеспечения и последующего обучения сотрудников принципам подготовки финансовой отчетности в соответствии с МСФО. Более того, высокая вероятность возникновения искажений в учетных данных дочерних организаций и более длительный срок подготовки конечной консолидированной финансовой отчетности, не делают данную систему менее привлекательной [3].

Если рассмотреть децентрализованный подход, то он подойдет более крупным компания, или компаниям, которые обладают значительными денежными средствами, которые они могут инвестировать в данный процесс. Но можно предложить для организации и другой подход. Подход будет носить более комбинированный характер. Принцип комбинированного подхо-

Таблица 1. Сравнительная характеристика систем автоматизации подготовки консолидированной финансовой отчетности.

\begin{tabular}{|c|c|c|c|}
\hline $\begin{array}{l}\text { № } \\
\Pi / \Pi\end{array}$ & Показатель & Децентрализованный подход & Централизованный подход \\
\hline 1. & $\begin{array}{l}\text { Стоимость внедрения в органи- } \\
\text { зацию }\end{array}$ & $\begin{array}{l}\text { Необходимы значительные } \\
\text { денежные средства }\end{array}$ & Экономное решение \\
\hline 2. & $\begin{array}{l}\text { Продолжительность разработки } \\
\text { и последующего внедрения в } \\
\text { организацию }\end{array}$ & $\begin{array}{l}\text { Процесс длителен и занимает } \\
\text { время }\end{array}$ & $\begin{array}{l}\text { Разработка и внедрения в крат- } \\
\text { чайшие сроки }\end{array}$ \\
\hline 3. & $\begin{array}{l}\text { Проведение организацион- } \\
\text { ных изменений и мониторинг } \\
\text { бизнес-процессов }\end{array}$ & Требуется & Не требуется \\
\hline 4. & $\begin{array}{l}\text { Подверженность рискам искаже- } \\
\text { ния информации }\end{array}$ & $\begin{array}{l}\text { Высокая точность достигается } \\
\text { отсутствием необходимости в } \\
\text { трансформационных и консоли- } \\
\text { дационных проводках }\end{array}$ & $\begin{array}{l}\text { Высока вероятность возник- } \\
\text { новения искажений в данных } \\
\text { дочерних компаний }\end{array}$ \\
\hline 5. & $\begin{array}{l}\text { Сроки закрытия отчетного } \\
\text { периода }\end{array}$ & В короткие сроки & $\begin{array}{l}\text { Может занимать более длитель- } \\
\text { ный промежуток }\end{array}$ \\
\hline
\end{tabular}


да будет заключаться в том, что материнская компания поделит свои дочерние компании на группы в зависимости от влияния на них. Можно предположить, что внедрение децентрализованного подхода, будет происходить по тем дочерним компаниям группы, которые существенно влияют на показатели финансовой отчетности группы или более вероятно данные компании находятся все время в экономическом взаимодействии, что в конечном счете приводит к большому количеству внутригрупповых операций. Данные операции исходя из консолидированной отчетности в последующем должны элиминироваться.

Переходя от подходов автоматизации подготовки консолидированной финансовой отчетности, необходимо определить основные программные средства, которые являются помощниками в формировании отчетности. В нашем случае выделяются четыре основных вида инструментариев, которые представлены на рисунке 2.

Основным программным продуктом, который используется повсеместно являются электронные таблицы. Самым распространённым в мире программным продуктом, который позволяет работать с документами, создавать формулы и подтягивать большие массивы данных является Microsoft Excel. Как и любой программе ей присущи свои недостатки и преимущества. К одному из преимуществ следует отнести интеграцию с большим количеством офисных приложений, уже предустановленных на компьютер и гибкую адаптацию таблиц к меняющимся требования. Также в таблицах предустановлен пакет формул, что дает проводить достаточно сложные расчеты без применения иных программных продуктов. К недостаткам можно от- нести отсутствие какого-либо главного централизированного хранилища информации, также таблицы имеют ограниченную архитектуру, отсутствует многомерность предоставления данных и при большом количестве организаций в группе, возможны ограничения скорости в выполнении операций.

Рассматривать заказные разработки бесполезно, так как объем информации ограничен и небольшое количество компаний пользуются ими.

Системы ERP (Enterprise Resource Planning управление ресурсами предприятия) [1] имеют большой плюс по сравнению с другими программными продуктами. Данные системы являются мультивалютными, что дает возможность совершать бухгалтерские и трансформационные проводки в разных валютах. Более того есть возможно формировать отчетность в разных валютах, что является несомненным плюсом при консолидации групп организаций. Данные системы являются достаточно дорогостоящими и сложными бизнес-системами. Каждая разрабатываемая система будет включать в себя дополнительно десятки блоков, которые автоматизируют все участки деятельности компании. Самыми известными системами ERP являются SAP ERP, Oracle ERP, MS Dynamics NAVISION, MS Dynamics AXAPTA.

Если организация ищет вариант, который будет обладать всеми возможностями, которые предоставляются ERP-системами и одновременно сохранять гибкость и функциональность относительно настроек администрирования, то такой организации более вероятно подойдут специализированные системы формирования и анализа консолидированной финансовой отчетности. Данные системы представлены одной

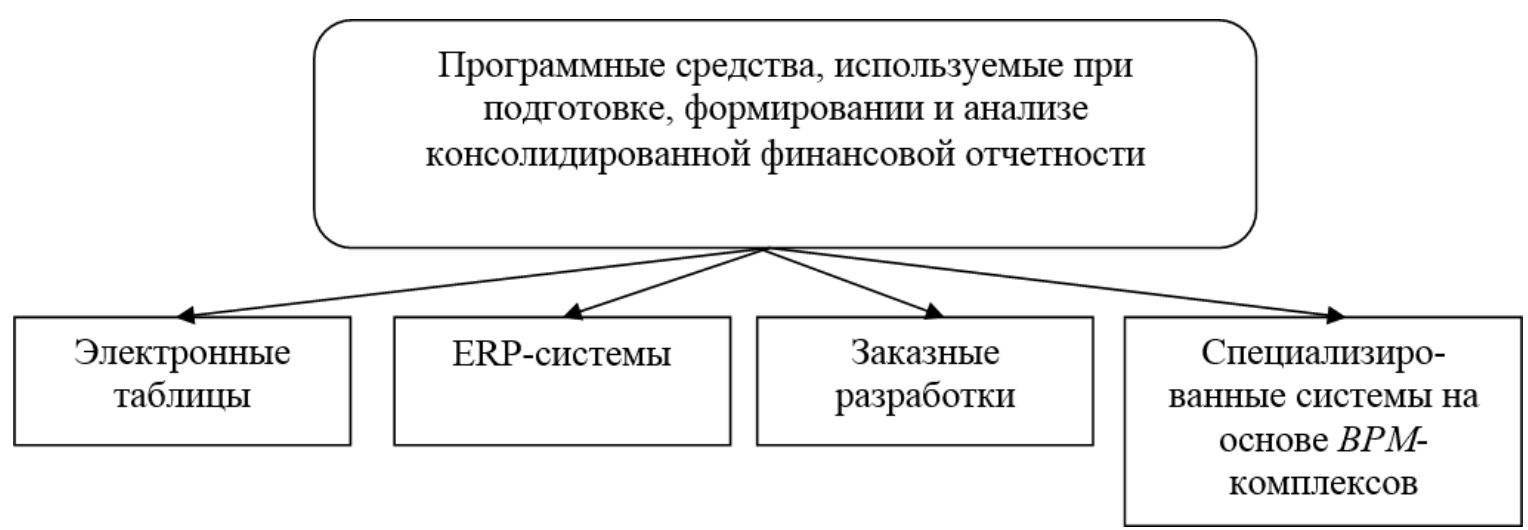

Рисунок 2. Программные средства, используемые при подготовке, и формировании консолидированной финансовой отчетности 
из составляющих систем управления бизнеса (Business Performance Management, BPM). Данные системы обладают широкими возможностями, особенно при использовании и интеграции разных учетных ERP-систем компаниями консолидированной группы. Представленные системы могут формировать консолидированную финансовую отчётность группы, на основе отчетности выявлять и оценивать эффективность Группы в целом. Основные характеристики и наиболее встречающиеся функции ВРМ системы будут представлены в приложении Е.

Эта система распределяется на функциональные модули и задачи, которая она способна решить. Модуль, отвечающий за целевое управление, может решать такие задачи как формирование целей развития через систему финансовых показателей. Также модуль ответственен за создание корпоративной системы мотивации сотрудников и оценку успешности заданной стратегии. Модуль бизнес-моделирования отвечает за формирование различных сценариев деятельности компании, а также за оценку возможных факторов, которые препятствуют выполнению поставленных целей. Основной задачей модуля, отвечающего за планирование и бюджетирование, является учет трендов с последующим анализом отклонения от факта, формирование бюджета для зависимых структур и бизнес-единиц и последующее планирование финансовых операций. Следующим модулем является бизнес-интеллект или ВІ. Он обладает мощным функциональными возможностями и основной задачей, которую он должен решать является формирование и структурирование анализируемой информации, ежедневный контроллинг финансового состояния компании и сбор финансовой и нефинансовой информации из различных подсистем и источников таких как (ERP, CRM, SCM и др.). Последними из наиболее важных модулей, которые относятся непосредственно к подготовке и формированию финансовой отчетность с последующей консолидацией и анализом, являются модуль «Финансовая консолидация, отчетность и анализ». Основной задачей данных модулей будет сбор финансовой отчетности дочерних компаний, выполнение трансформационных и консолидационных проводок, формирование комплекта финансовой отчетности и последующий анализ проведенной работы.

Наиболее известной зарубежной системой, представленной американским разработчиком Oracle, является Oracle's Hyperion Financial Management. Данная система широко представлена как за рубежом так и в России, и многие крупные компании пользуются данной системой для формирования консолидированной финансовой отчетности. Данная программа обладает следующими особенностями, которыми не обладают другие программы. Это масштабируемость веб-архитектуры, полный аудиторский след, мощная аналитическая компонента для построения отчетности и анализа и консолидация плановых и прогнозных данных и обеспечение последующего контроля за их выполнением. Основным преимуществом, которым обладает данная программа перед программами других разработчиков это:

1) сокращение времени цикла консолидации;

2) снижение количества ошибок благодаря единому источнику данных;

3) обеспечение глубокого анализа финансовых показателей;

4) интегрирование с прочими приложениями пакета.

Таким образом данная программа обладает всеми функциями и возможностями для беспрепятственного формирования консолидированной финансовой отчетности в кратчайшие сроки. Если переходить к российским разработчикам программного обеспечения, то в нашей стране преобладает система 1С Управление холдингом. Многие российские компании используют ее так как она обладает такими особенностями как: план-факт анализ, казначейство, моделирование и прогнозирование финансовой деятельности компании и многомерная финансовая отчетность. Основными преимуществами российской системы выделяют такие как: нормирование ресурсов и установление лимита расходов, быстрая интеграция новых филиалов и дочерних компаний в бюджетный процесс и возможность оперативного получения достоверной отчетности различного назначения.

Каждой организации, которая задумывается о покупке той или иной автоматизированной системы, необходимо просчитать расходы, которые будут понесены при покупке данного программного обеспечения и более того расходы на обучение персонала и последующие обновления самого программного обеспечения. В данном случае и кроется главный недостаток, любой из 
вышеперечисленных систем. Например, для 1C Управление холдингом только покупка и внедрение программного обеспечения в зависимости от размера компании будет составлять от 5 до 30 млн. руб. Для иностранного программного обеспечения такого как HFM, цена является конфиденциальной и определяется в зависимости от самого клиента. Поэтому, можно предположить, что цена более вероятно будет выше, чем рассмотренный ранее российский аналог.

Методические рекомендации по составлению консолидированной финансовой отчетности для группы организаций банковской сферы в настоящее время отсутствуют. В прошлом еще до введения стандарта МСФО 10 о консолидированной финансовой отчетности, существовали «Методические рекомендации по составлению консолидированной отчетности» введённые в действие еще в далеком 2004 году для банков. В наше время каких-либо рекомендаций, относящихся полностью к процессу формирования консолидированной финансовой отчетности не существует, так как основную роль на себя взял стандарт МСФО 10.

Рассматриваемые два банка ПАО КБ «Центр-инвест» и АО «Тойота Банк» не использовали каких-либо специализированных программ консолидации финансовой отчетности, которые были призваны для упрощения и ускорения процесса консолидации. Напротив, они использовали централизированный подход, при котором банк собирал отчетность своих дочерних компаний по РСБУ, а потом проводил трансформационные корректировки для представления данной отчетности в МСФО. Как мы видим, оба банка, пошли по данному пути и это может объясняться следующими причинами:

1) несущественная доля дочерних компаний в общей структуре банка;

2) дочерние компании представлены в разных отраслях никак не связанные с кредитным рынком;

3) разная методология бухгалтерского учета и плана счетов.

В результате, можно прийти к выводу, что сложность и затратность процесса консолидации финансовой отчётности зависит от специфики деятельности организации, её размеров и степени сложности структуры организации. Необходимо отметить, что каждой отдельной организации следует индивидуально подбирать методику трансформации финансовой отчётности в формат МСФО таким образом, чтобы она подходила всем перечисленным параметрам. Использование унифицированной методики любой компанией не позволит учесть все особенности её функционирования и, возможно, приведёт к нерациональному распределению ресурсов на подготовку финансовой отчётности по МСФО.

\section{Библиографический список}

1. Сидорова М.И. Современные информационные технологии как инструмент автоматизации бухгалтерского учета // Международный бухгалтерский учет. 2019. № 28.

2. Выручаева А.Е. Рекомендации по устранению ошибок в МСФО-отчетности // Корпоративная финансовая отчётность. Международные стандарты. 2019. URL: https://finotchet.ru/articles/273.

3. Козлова Н.В. Информационные технологии для подготовки консолидированной финансовой отчетности // Санкт-Петербургский государственный экономический университет, - 2018. - С. 120-121.

4. Петров А.М. Инновационные процессы составления консолидированной отчетности // Учет. Анализ. Аудит. - 2019. - № 5.- С. 34-40.

5. Мысева E.P., Лукьянова Т.О. Особенности консолидированной финансовой отчетности и ее анализа // Научно-практический электронный журнал Аллея Науки - 2018. - № 10. - С. 384-387.

6. Солдаткина О.А. Саулина Ю.Д. Проблемы составления консолидированной финансовой отчетности группами компаний // Сборник научно-технический прогресс как фактор развития современной цивилизации - 2017.- С. 159-163. 